\title{
Función de la imagen gráfica en el discurso académico y profesional: aplicación a un corpus de revistas podológicas
}

\author{
Function of graphic images in academic and professional \\ discourse: an application to a corpus of podiatric journals
}

ABSTRACT: Based on a corpus of podiatry journals, this article analyzes the different degrees of figurativeness or iconicity of the illustrations, and their functions in journal discourse. This subject is approached from the perspective of the management of such knowledge in the macro-genre professional magazine in so far at it is relevant for their contribution to the construction of this health profession.

Keywords: graphic illustration, professional magazine, professional community, podiatry, figurativeness.

RESUMEN: A partir de un corpus de revistas profesionales del mundo de la podología, este artículo analiza los distintos grados de figuratividad o iconicidad de las ilustraciones y sus funciones en el discurso. Todo ello se enfoca desde la perspectiva de la gestión de dichos conocimientos en el macrogénero revista especializada y en cuanto que resulta relevante para su contribución a la construcción de esa profesión sanitaria.

Palabras clave: ilustración gráfica, revista especializada, comunidad profesional, podología, figuratividad. 


\section{El (macro-)género revista profesional podológica}

Las publicaciones científicas especializadas en podología inician su trayectoria en España de forma simultánea con el desarrollo de la disciplina, con el aumento del número de profesionales y con la creación de centros de estudio de la especialidad. Sin duda estos avances están motivados en gran medida por el aumento de la demanda social de estos profesionales sanitarios. Las revistas especializadas de podología no son numerosas, pero cabe apuntar como dato característico, y tal como ocurre en otras especialidades sanitarias de corta trayectoria, que presentan gran difusión en la comunidad a la que van dirigidas, pues la mayor parte de ellas son de distribución gratuita a través de los colegios profesionales territoriales, o por el Consejo General de Podólogos.

Para definir el género revista profesional -que aquí denominaremos macrogénero, como marco donde se alojan géneros tales como editoriales, artículos de revisión, originales o casos clínicos- se hace necesario contextualizar, aunque sea de manera sucinta, algunos aspectos clave de la profesión podológica, haciendo hincapié sobre todo en su evolución como profesión liberal y su estatus académico.

Los estudios de podología fueron durante años una especialización de la enfermería. En los años ochenta, la podología se convirtió en una diplomatura universitaria que la diferenciaba de otras ramas del saber clínico y científico. En la última época, desde la integración de todas las titulaciones en el marco europeo de Educación Superior, los estudios de esta profesión han alcanzado el estatus de grado universitario. El colectivo profesional podológico ha tenido en cuenta, desde el establecimiento y normalización de esta disciplina como saber médico, que es necesario un medio donde los profesionales compartan experiencias y sobre todo informaciones e ideas gremiales. Estas últimas cuestiones son las que constituyen la profesión internamente y generan su identidad propia. Así, podemos imaginar cómo el macrogénero revista profesional se caracteriza por unas peculiaridades muy especificas, entre ellas las imágenes gráficas incluidas en los diferentes géneros que constituyen la revista profesional.

El corpus de análisis utilizado para elaborar el presente artículo consiste en una muestra de las revistas especializadas profesionales en el campo de la podología, concretamente las siguientes: Revista Española de Podología, El peu y la denominada revistadepodologia.com, en los números correspondientes a los años 2005, 2006 y 2007. 


\section{Las escalas de figuratividad}

Hoy día, en la época de la mediosfera, somos más conscientes que nunca de que las prácticas comunicativas integran distintos sistemas semióticos en el seno de lo que se suele denominar multimodalidad. En el ámbito de la ciencia y en el de su difusión social, la imagen gráfica entra en una dialéctica muy productiva con el texto escrito, particularmente relevante en disciplinas como las biomédicas, donde la anatomía, la cirugía o la ortopedia son campos relevantes del conocimiento que requieren la identificación de entidades y procesos a través de imágenes.

Ciertamente, la contraposición entre imagen visual y signo verbal (oral o escrito) es una dicotomía esquemática que ha dado mucho juego en la cultura popular, como se observa en el celebérrimo proverbio «una imagen vale más que mil palabras». Hoy día, en la época de la cultura digital y de la mediosfera, somos conscientes de la inexactitud de la dicotomía, puesto que son flagrantes las pruebas de que las prácticas comunicativas integran, sobre todo con la flexibilidad que las nuevas tecnologías facilitan, no solo dos sino diversos códigos semióticos en el seno de lo que se suele denominar multimodalidad (Payrató, 2012).

Si regresamos al tema concreto de este trabajo, las revistas especializadas de nuestro corpus presentan una integración, más o menos acertada según los casos, entre la semiosis del texto escrito y las imágenes visuales de distintos tipos. Este asunto presenta sin duda una elevada complejidad para los no especialistas en el estudio de la imagen y de su relación dialéctica con el texto escrito:

La diversité des sciences productrices d'images, la pluralité des fonctions qui leur sont attribuées en science, et leur évolution au cours de l'histoire achèvent de complexifier par avance une tentative de définition générale. (Bontems, 2011: 90)

El asunto de la utilidad de las imágenes visuales para la trasmisión de los conocimientos conceptuales y práctico-tecnológicos ha suscitado el interés de numerosos estudiosos. Así, por ejemplo, la revista/colección Visible dedicaba recientemente un monográfico al tema de la imagen científica (Allamel-Raffin y Moktefi, 2011), con varias aportaciones relevantes para nuestra investigación.

La imagen es un elemento que constituye invariablemente un apoyo didáctico e ilustrativo al texto escrito. En el campo científico adopta diferentes representaciones como las figuras diagramáticas de la estadística, o bien la imagen clínica de un estado patológico o el simple dibujo descriptor sintético de 
una técnica, pero resulta difícil ofrecer una definición completa y funcional que comprenda la totalidad de representaciones que constituye la imagen dentro de un discurso especializado. A este respecto, Bontemps (2011: 89) apunta:

La définition générale de l' «image scientifique» soulève des difficultés quant à son extension comme sa compréhension. La procédure bachelardienne de l'«analyse spectrale» permet de les lever en élaborant une notion d'image fondée sur sa production phénoménotechnique et dont la valeur opératoire est distribuée selon les horizons théoriques.

Cada disciplina científica suele utilizar en mayor o menor medida un tipo de representación u otra. Así, en el caso de las matemáticas las más frecuentes son fórmulas, mientras que en los tratados de anatomía las imágenes fotográficas descriptivas constituyen la fuente casi exclusiva de representación. Es por ello que así queda fijada al texto una tipología de imagen según la especialidad, como refiere Bontemps (2011:90):

[...] elle dépend largement de la discipline qui la prend pour objet d'étude: la philosophie, la sociologie, la sémiotique, la sémiologie, ne partagent pas les mêmes présupposés sur les caractéristiques des objets recevables en tant qu'image.

Al respecto de la virtualidad didáctica de las imágenes, resulta relevante la opinión de Valero Sancho (2001:165), vertida en su libro sobre la importancia de la infografía en el periodismo:

Creo en la didáctica de las infografías y pienso que no es únicamente en las aulas o los libros de enseñanza donde está claro que se deben incorporar, sino en todos los procesos de información que se emplean para instruir a la sociedad y especialmente en la prensa diaria, donde las informaciones no siempre son fáciles de explicar de manera comprensible, y además a veces no se entienden bien si no se exponen convenientemente asuntos laterales sin los cuales en ocasiones no se puede comprender el aspecto más significativo de la información.

En el orden de la didáctica estricta, y más en concreto de los libros de texto de física, la aportación de Perales y Jiménez (2002) resulta de aplicación pertinente, así como el trabajo de Prieto Velasco (2007) sobre el uso de ilustraciones en el discurso científico técnico. Uno de los parámetros principales que se incluyen en la mayoría de los trabajos citados es el del grado de iconicidad o abstracción de las imágenes: 
La iconicidad se ha revelado como un factor semiótico muy importante a la hora de representar conceptos que aluden a objetos materiales y, especialmente, para hacer accesibles algunos conceptos complejos representativos de objetos inmateriales, es decir, conceptos abstractos, no directamente perceptibles por los sentidos. Por tanto es en los textos divulgativos y semiespecializados donde estas ilustraciones desempeñan un papel de gran utilidad. (Prieto Velasco, 2007: 155)

Las revistas estudiadas aquí pueden situarse en un punto intermedio de ese arco de especialización, como revistas semiespecializadas o semidivulgativas, ya que en última instancia responden al objetivo de la formación continuada de los profesionales del gremio. Por eso la imagen desempeña un papel importantísimo en la mostración de objetos y en la configuración de un discurso procedimental de instrucciones transparentes y efectivas. En efecto, la explicación de la diagnosis y de las técnicas de abordaje terapéutico del paciente precisa a menudo de la imagen como factor de explicitación eficiente. A todo ello habría que añadir que la naturaleza misma del objeto de estudio de esta disciplina exige con más frecuencia que en otras la concreción de imágenes de distintos elementos anatómicos. En síntesis, tanto el carácter aplicado y frecuentemente instruccional de las revistas como, por otra parte, la misma naturaleza de la temática estudiada confluyen en la conveniencia de la mostración de imágenes visuales que se insertan así en este tipo de discurso.

Por lo que se refiere al grado de iconicidad de esas imágenes, hay que decir que este es heterogéneo pero que manifiesta una notable proclividad a situarse en un punto alto de la escala. Podríamos establecer un recorrido de la escala correspondiente en los siguientes términos en cinco estadios de iconicidad decreciente: 
- Fotografías generalmente en color relacionadas con la especialidad (ilustración 1).

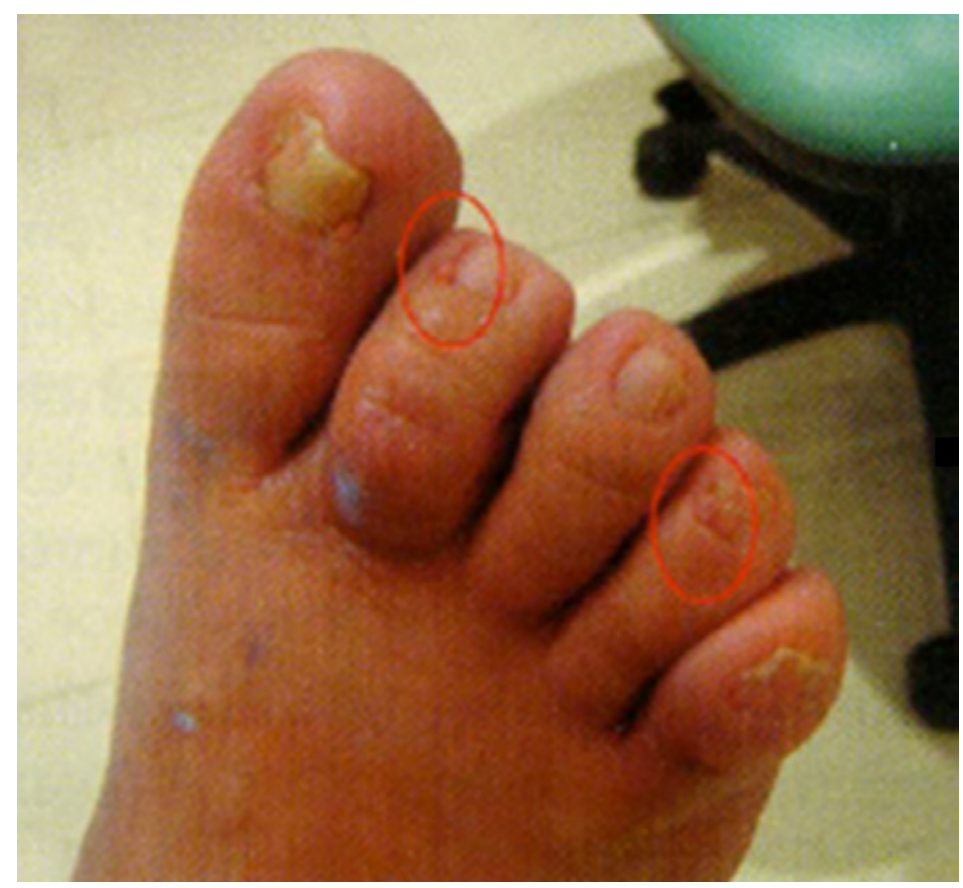

Ilustración 1: Imagen extraída de la $\operatorname{REP} 2005$, n. ${ }^{\circ}$ 5: 218

- Secuencias de la realización de procedimientos terapéuticos (ilustración 2). Podemos considerar que esta técnica representativa corresponde a un grado levemente menor de iconicidad, ya que el parámetro de dinamismo o movimiento de las imágenes de un proceso real (Prieto Velasco, 2007: 139-141) resulta congelado por su segmentación a lo largo de una secuencia de fotos fijas. La misma representación de la marcha humana, tan importante desde el punto de vista podológico, también se ve afectada en estas publicaciones por ese mismo filtro amortiguador de la iconicidad. Dicho de otro modo: el proceso continuo que se produce en la realidad queda aquí congelado y segmentado, convencionalmente en una serie de imágenes fijas. El proceso, por lo tanto, está más «manipulado». 


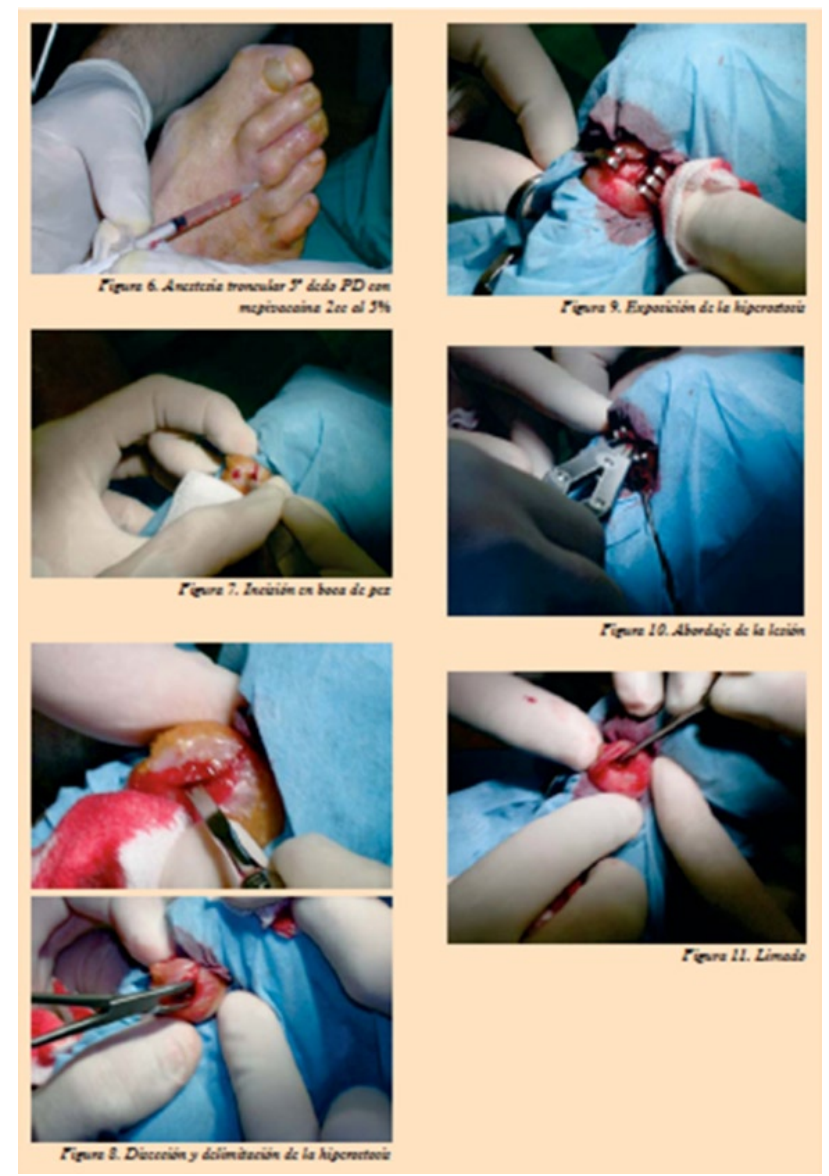

Ilustración 2: Imagen extraída de la revista $E l$ peu 2005, n. ${ }^{\circ}$ 3: 141

- Otro grado en la escala de iconicidad consiste en la reproducción fotográfica de imágenes derivadas de la aplicación de instrumental diagnóstico, como por ejemplo las radiografías o los mapas de presiones plantares obtenidas con el aparataje correspondiente (ilustración 3). En este capítulo entraría, por un lado, la visualización tecnológica de elementos anatómicos internos como son las estructuras óseas que se visibilizan por medio de radiográficas y, por el otro, el comportamiento del pie en dinámica y estática valorado mediante presiones plantares. En otras áreas de las ciencias de la salud se daría un caso semejante con elementos como el electrocardiograma. 


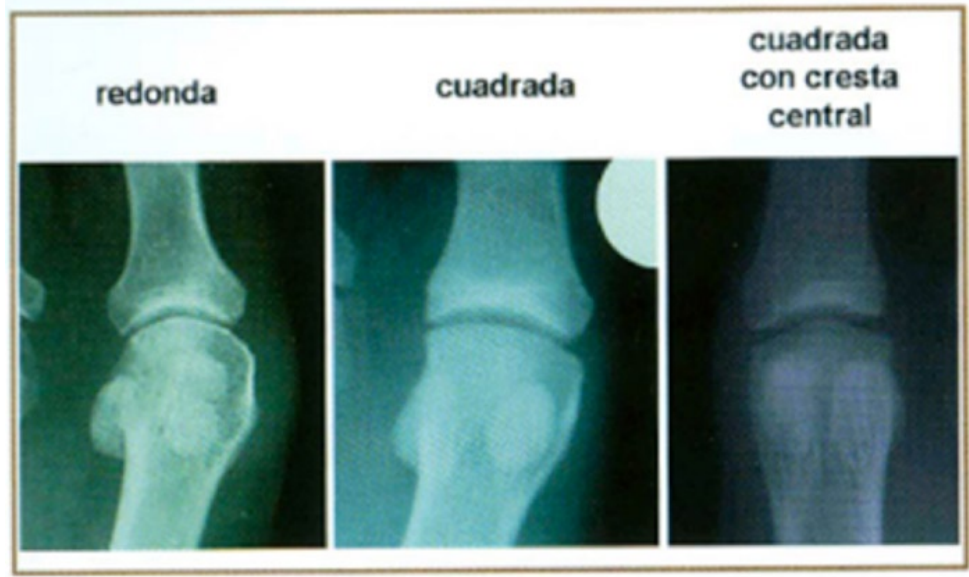

Figuro 1. Closficación trodicional de lo formo de lo cabezo del primer metotarsiono.

Ilustración 3: Imagen extraída de la $R E P$ 2007, n. ${ }^{\circ}$ 2: 65

- Dibujos y croquis. Se trata aquí de representaciones esquematizadas de objetos reales que generalmente son elaboradas para la publicación donde aparecen: atlas anatómicos, esquemas mecánicos, representaciones elaboradas (ilustración 4).

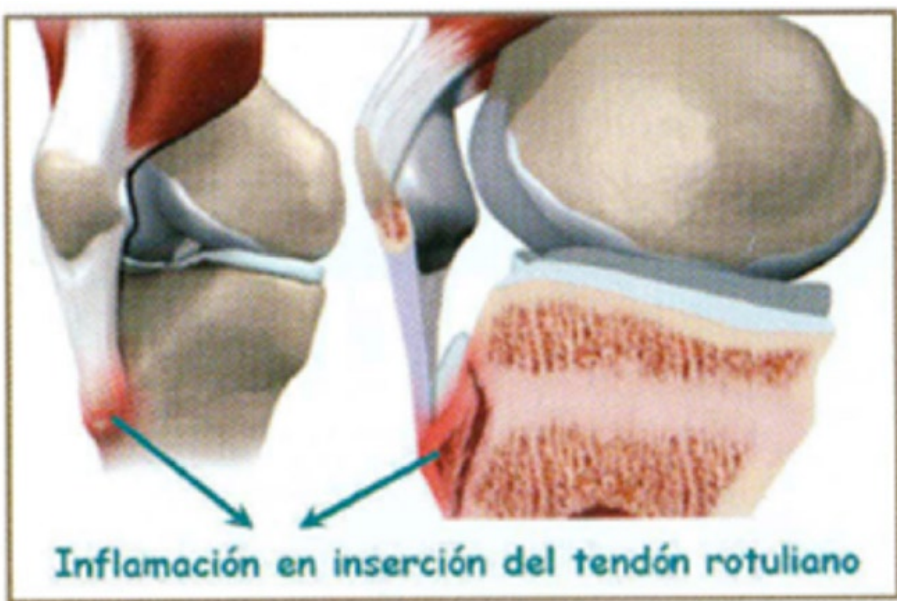

Figuro 2. "Lo enfermedod de Osgood - Schlarter se desarrollo en la tuberosidad anterior de lo ribio."

Ilustración 4: Imagen extraída de la REP 2007, n. ${ }^{\circ}$ 2: 92 
- Figuras diagramáticas que suponen un grado de abstracción superior, ya que no representan un objeto físico ni un proceso material, sino que constituyen signos de conceptos, relaciones o procesos de orden intelectual (ilustración 5). A fin de cuentas, el estudio médico del cuerpo no es tan solo el examen y la descripción de unas estructuras físicas, sino que ha de incorporar un nivel alto de abstracción para su conceptualización adecuada y para la comprensión holística de su realidad y su funcionamiento (ilustración 6). Así lo indica Novello Panglianti (2011: 228):

Le dessin corporel en médicine est en tension entre sa capacité référentielle et sa capacité d'abstraction qui est justifiée par l'objet même, le corps, qui se présente «naturellement» en strates complexes et difficilement lisibles. La pratique du médecin s'articule, comme le dessin dans une tension entre l'établissement d'un diagnostic constitué par les données sensibles du corps (symptômes) du malade et les connaissances plus techniques et abstraites. La position du médecin comme interprétant permet l'ajustement entre ces deux pôles.

Se incluirían aquí los mapas conceptuales y también las tablas o figuras estadísticas propias de la investigación cuantitativa aunque estas suelen aparecer exclusivamente en el género de los artículos originales de investigación. Todos estos tipos de diagrama comparten generalmente una función cognitiva de extraordinaria relevancia, como explica Giardino (2011: 191):

Tout d'abord, on trouve que dans certaines tâches, les diagrammes sont plus avantageux que les représentations linguistiques. [...] De surcroît, les diagrammes représentent également un avantage cognitif par rapport à la référence au calcul mental, précisément parce que les diagrammes sont des outils extra-mentaux qui permettent d'alléger la charge cognitive exigée de la mémoire de travail. 


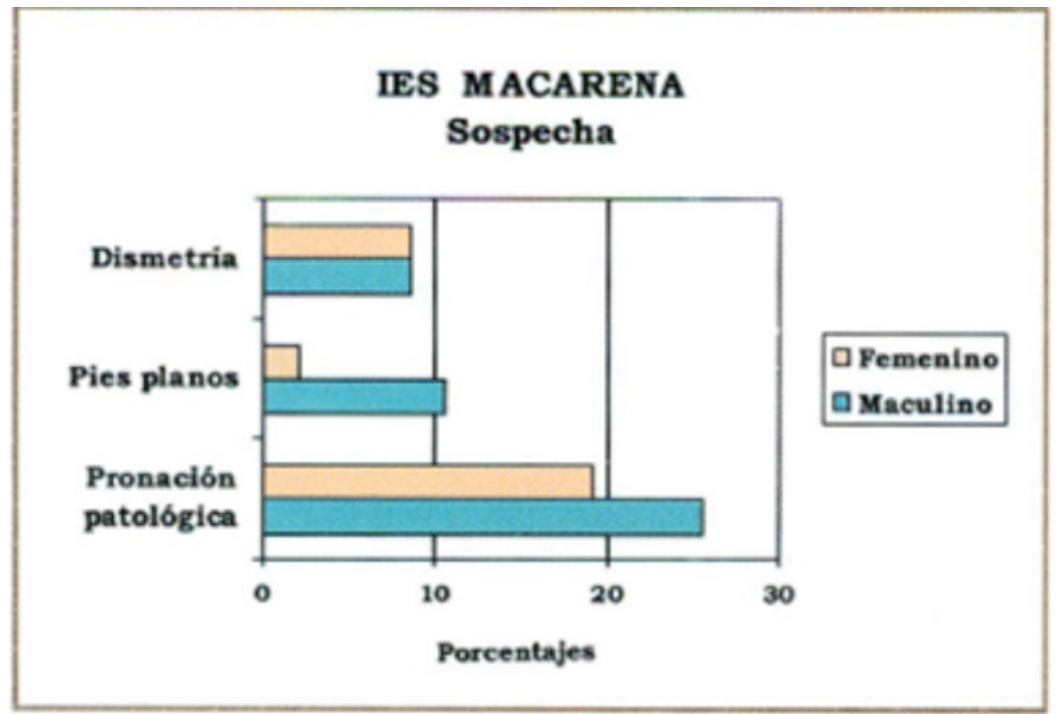

Figuro 1

Ilustración 5: Imagen extraída de la REP 2006, n. ${ }^{\circ}$ 6: 280

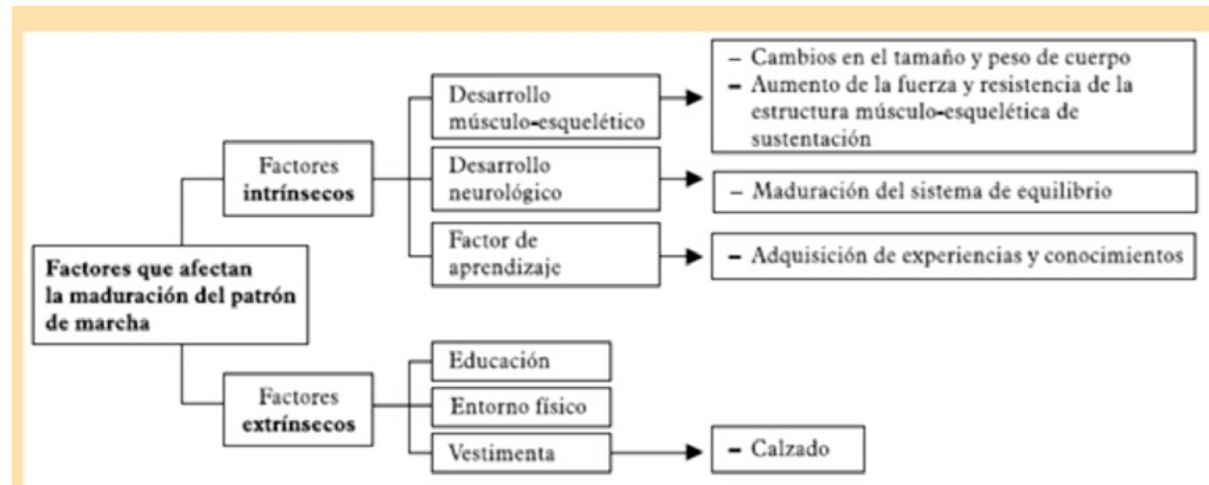

Figura 1. Esquema de los factores que afectan al niño durante la maduración de su patrón de marcha

Ilustración 6: Imagen extraída de la revista $E l$ peu 2005, n. ${ }^{\circ} 1: 10$ 


\section{Funciones de las imágenes en el discurso}

Además del parámetro de la iconicidad, se pueden clasificar las ilustraciones de las revistas podológicas a partir de un criterio de funcionalidad, con el que establecer las siguientes categorías aproximativas, de una manera menos claramente delimitada que en la clasificación anterior.

- Imágenes con función ornamental que se limitan a embellecer, adornar o ilustrar de manera poco operativa la exposición plasmada en el texto siguiente. Así por ejemplo, en el caso de uno de los artículos de la sección «Rincón de la imagen» de la revista $E l$ peu y ante la escasez de ilustraciones pertinentes del fenómeno histórico del pie de loto tal como se daba en la cultura china primitiva, el autor procede a insertar una fotografía de una especie de consulta podológica callejera que tiene, al parecer, una sola motivación de relleno gráfico para aligerar el peso del texto escrito. Otro ejemplo que se sitúa en el límite entre lo meramente ornamental y el guiño cómplice al especialista es el de la imagen que reproduce el célebre cuadro del nacimiento de Venus pintado por Botticelli. El autor del texto (revista $\mathrm{El} \mathrm{peu}$ ) añade en el pie de foto una referencia a los trastornos estáticos del pie de la figura femenina (un pie plano y otro cavo valgo) (ilustración 7).

- Ilustraciones necesarias o muy convenientes para complementar el texto escrito y que representan específicamente factores relacionados directamente con el miembro inferior. Este apartado corresponde a imágenes íntimamente relacionadas con los contenidos expuestos y que no constituyen un simple paliativo de la densidad textual, sino que establecen con la dimensión verbal una sinergia altamente productiva con la dimensión verbal: mientras que el texto sostiene el conjunto del discurso narrativo o argumentativo, las ilustraciones muestran aspectos parciales. En otras palabras, la información incluida en las imágenes es discontinua y solo su inclusión en el conjunto le da significado (Perales y Jiménez, 2002: 377). 


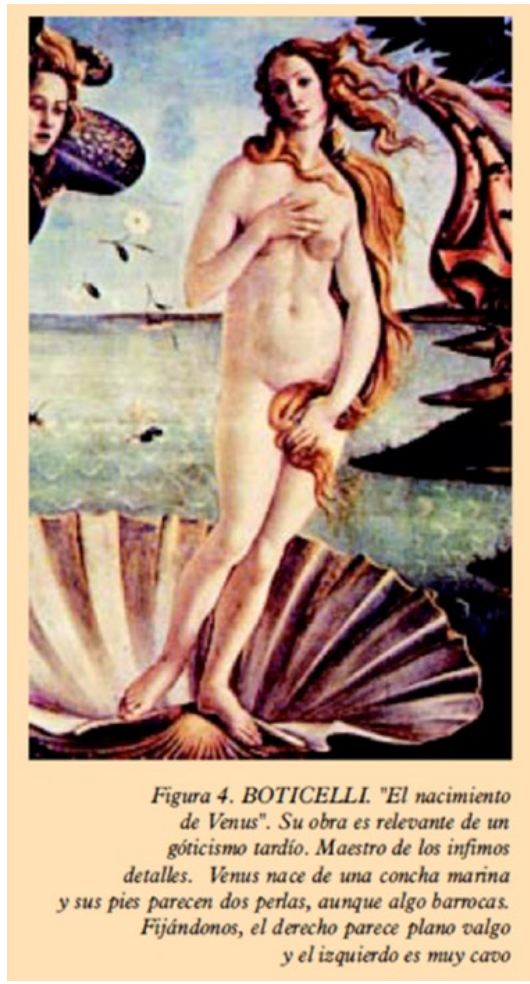

Ilustración 7: Imagen extraída de la revista $E l$ peu 2005, n. ${ }^{\circ}$ 1: 12

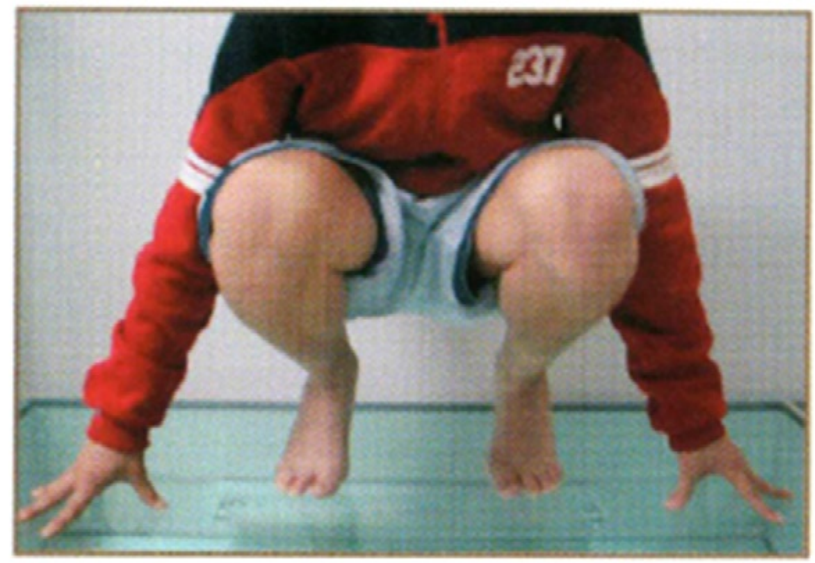

Figuro 9. "Posidión en le cual se reproduxen los microtroumatiomos de repetición".

Ilustración 8: Imagen extraída de la $\operatorname{REP} 2007$, n. $^{\circ}$ 2: 93 
- Elementos periféricos de la representación de las partes anatómicas correspondientes al miembro inferior, así como sus funciones y disfunciones fisiológicas, que han de ser con frecuencia contextualizadas, es decir han de ir complementadas con la presentación de otras partes del cuerpo humano, como por ejemplo las piernas, o incluso la totalidad de la figura corporal por necesidades explicativas y por requerimientos propios de la especialidad para la comprensión adecuada de los conocimientos expuestos (ilustración 8). Un caso particular de especial relevancia entre estos elementos periféricos es el del calzado, ya que representa un complemento y una defensa del pie en su interacción con el medio ambiente. El calzado precisamente puede constituir asimismo un factor de distorsión y un motivo de alteraciones y dolencias en el pie a causa de costumbres impuestas por la tradición (como en el caso de la antigua China) o por modas perjudiciales para la salud podológica (de manera muy especial en lo que se refiere al calzado femenino). En su conjunto, pues, el calzado constituye un artefacto de incidencia decisiva, en el sentido positivo o bien negativo para la salud podológica, e incluso puede y debe relacionarse con el ámbito de la ortopodología, sobre todo cuando se le añade el elemento de los soportes plantares. En este sentido, las ilustraciones referentes a este complemento adquieren una funcionalidad muy notable en el desarrollo del discurso podológico en general y en el de las revistas especializadas en concreto (ilustración 9). Con el tratamiento de este aspecto, además, entramos ya en el área de la categoría siguiente que es la de las imágenes de contenido instrumental (ilustración 10). 


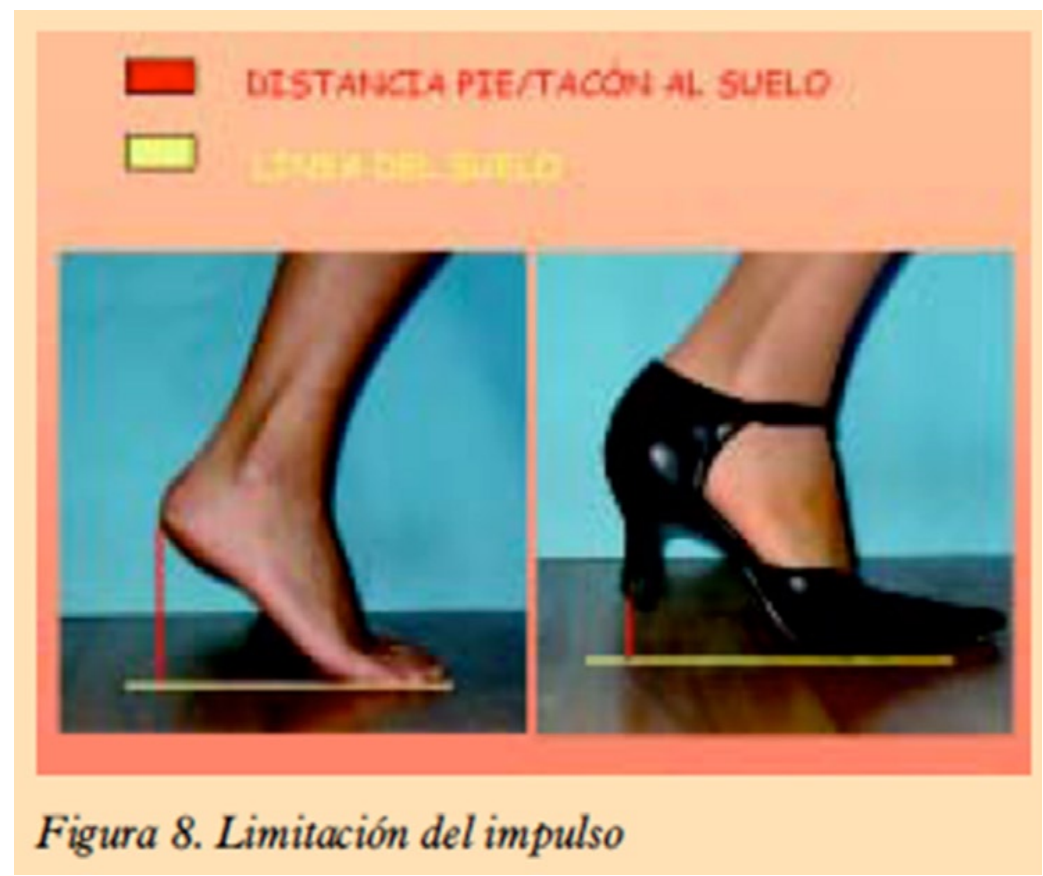

Ilustración 9: Imagen extraída de la revista $E l$ peu 2005, n..$^{\circ}$ 2: 90

- Imágenes de recursos instrumentales. Habida cuenta de que la finalidad de las revistas podológicas no se limita a la descripción de la extremidad inferior y de sus elementos periféricos, sino que apunta en la dirección de instruir a los lectores sobre procedimientos de diagnóstico y de tratamiento, la presentación, descripción y valoración de los instrumentos oportunos ocupa un lugar destacado en los contenidos y requiere en buena medida de una mostración visual. Novello Paglianti (2011: 220) sintetiza así esta pluralidad de perspectivas que concurren en el estudio anatómico en general:

L'anatomie est donc partagée entre trois variables: le savoir, la technique et la mise en pratique des acquisitions. Ce processus est ordonné en crescendo et l'ensemble de ces composantes ne peut être réduit à la simple somme des trois. Par exemple, la formulation du diagnostic, comme suite logique de ce processus, prend appui sur ces trois moments. 
Gran parte de las ilustraciones de nuestras revistas responden a esta integración de los tres «momentos» del saber teórico-descriptivo, la aplicación y la práctica. Insistimos aquí especialmente en lo que se refiere al instrumental diagnóstico y terapéutico.
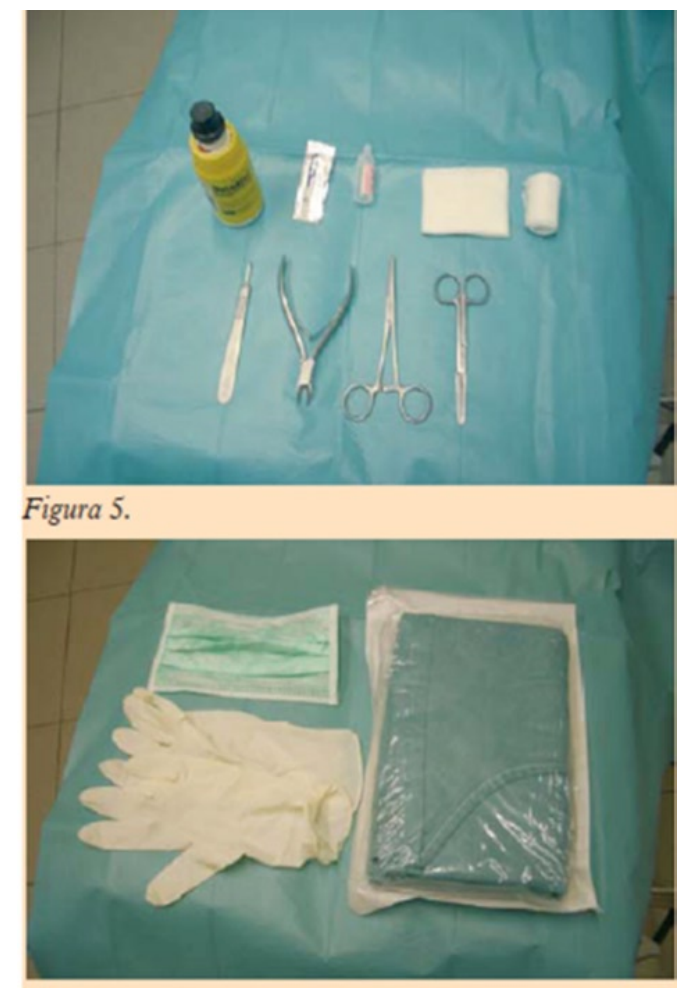

Figura 6.

Ilustración 10: Imagen extraída de la revista $E l$ peu 2005, n. ${ }^{\circ}$ 3: 130

Podemos observar, como lectores de las revistas de especialidad, que existe todo un imaginario sobre las figuras o ilustraciones que se esperan en cada tipología de artículo. El resultado viene dado por las normas que cada revista indica estrictamente para la inserción de imágenes e ilustraciones en cada sección. Estas indicaciones intentan ajustarse a la naturaleza del estudio y se adecúan extraordinariamente a la tipología de artículo y sección. Es por ello que resulta fácil de imaginar cómo el lector esperará un tipo de imagen o representación en función del tipo de artículo que está leyendo. Nos centraremos ahora en el detalle de estas modulaciones, aunque cabe subrayar que, como era de esperar, 
los géneros o secciones que no tienen contenido clínico, y en primerísimo lugar los editoriales, no suelen incluir ilustraciones de ningún tipo. Un caso aparte es el de los anuncios publicitarios. Debemos apuntar que no vamos a considerar las ilustraciones de la publicidad inserta en las revistas de nuestro corpus, ya que ese tipo de ilustración debe ser tratado desde su propio punto de vista y no desde el análisis y caracterización didáctico que proponemos ahora.

En cambio, sí que vamos a dedicar ahora un espacio específico a una sección fija de la revista $E l$ peu donde la imagen adquiere un protagonismo casi absoluto: «Rincón de la imagen».

\section{Una sección específica para glosar imágenes}

«Una imagen vale más que mil palabras» es el proverbio con el que hemos iniciado este trabajo y también en este proverbio parece sustentarse la sección titulada «Rincón de la imagen» de la revista El peu. Las imágenes constituyen hoy en día una herramienta fundamental formativa en las profesiones sanitarias y deben estar contextualizadas, explicitadas y además deben ajustarse a la realidad clínica de los lectores de las revistas especializadas.

Tradicionalmente las imágenes que tienen como función la formación e instrucción para un posterior reconocimiento clínico son imágenes reales de diferentes patologías podológicas o deformidades en estadios medios y localizaciones tradicionales ya que, por norma general, en una sociedad con tradición clínica y médicamente avanzada, son pocos los casos donde los pacientes presentan los últimos estadios y exacerbaciones de las enfermedades podológicas.

Es cierto que el pie y el miembro inferior son localizaciones anatómicas donde se asientan multitud de enfermedades de muy diversos orígenes que pueden pertenecer para su curación a diferentes especialidades clínicas y médicas. Esta circunstancia motiva la especial formación e instrucción que los profesionales podólogos/as deben poseer en su cuerpo de conocimiento clínico con la finalidad de reconocer y diagnosticar las manifestaciones clínicas patológicas que no pertenecen estrictamente a su especialidad.

Justo aquí en este punto, es donde la sección «Rincón de la imagen» de la revista $E l$ peu encuentra su motivación y justificación como sección fija de esta publicación. Antes de entrar en la descripción de los contenidos y su análisis, es conveniente contextualizar esta sección.

«Rincón de la imagen» está situado, dentro de la revista, en penúltimo lugar. Le precede la sección de casos clínicos y tras ella encontramos la agenda 
de la revista. La localización ya deja inferir la poca importancia que se le da a esta sección que ahora analizamos, la cual cuenta en nuestro corpus con un total de doce artículos. No existe un apartado homólogo en las otras dos revistas de nuestro corpus, ni género que podamos comparar. Ahora bien, no está de más señalar cuál es el posible origen del «Rincón de la imagen» si comparamos la revista El peu con la revista Japma. En esta última revista norteamericana, titulada Journal of the American Podiatric Medical Association, podemos encontrar una sección denominada «Clínicamente ilustrado» (Clinically Illustrated), donde el editor explícitamente, en las normas de publicación y edición de textos originales, demanda que los artículos dirigidos a esta sección estén basados en imágenes clínicas o de técnicas novedosas donde predomine la potencia de la imagen y su explicitud en lugar del texto que la acompaña.

Las ilustraciones del «Rincón de la imagen» pueden ser consideradas como imágenes impactantes que despiertan el interés del lector por su alto grado de patogeneidad. Es decir, son imágenes poco frecuentes relacionadas con patologías podológicas estrictas y sobre todo con patologías sistémicas con repercusión en el pie. En esta última circunstancia es donde reside el interés de esta sección, ya que el «Rincón de la imagen» ofrece de manera didáctica, y sobre todo muy explícita, la posibilidad de aprendizaje de aspectos clínicos poco frecuentes en la actividad asistencial. Podíamos pensar que en el ámbito de una ciencia médico-clínica como la podología, no es necesario este tipo de artículos ni de formación y, mucho menos, en un soporte de revista especializada. Pero la realidad formativa deficiente/arcaica, y en muchos casos no actualizada de una parte del colectivo de podólogos/as, hace que este tipo de artículo se haga necesario dentro del gremio y, más concretamente, en una revista especializada colegial.

Es cierto que en el aprendizaje del arte de la diagnosis, además de todos los elementos clínicos que rodean a la situación clínica, es fundamental la capacidad de memorización y reconocimiento de lesiones y patologías que proveen al clínico de un arma diagnóstica insustituible. Por ello, el «Rincón de la imagen» opera dentro de las revistas de especialidad, y en este caso concreto de la podología, como instrumento formador y de adiestramiento de la capacidad clínica y diagnóstica de sus lectores. Veamos ahora un par de ejemplos de definición ostensiva, para lo cual haremos valer un artículo de la revista El peu n. ${ }^{\circ} 3$ de 2007, donde el autor inicia el texto haciendo referencia a las imágenes de esta manera: «En las imágenes observamos distintos grados de sindactilia». Es evidente que aquí la imagen se convierte en la propia definición (una definición ostensiva o mostrativa), quizás porque sea mucho más económico y didáctico 
ofrecer la imagen y no complicar su comprensión con una definición compleja y de difícil redacción (ilustración 11).

\section{Rincón de la imagen}

Jose $\mathbf{M}^{2}$ Camero Elias. Podologo

carnercelias(a wanadoo.es

\section{Sindactilia}

En las imágenes observamos distintos grados de sindactilia.

La unión de los dedos que en ocasiones se limita a la membrana interdigital $\mathrm{g}$ otras ocasiones, implica la fusión a nivel óseo.

En su forma más común, presenta la fusión del segundo $y$ el tercer dedo del pie $y$ a menudo es un trastorno hereditario frecuente. Además, la sindactilia puede presentarse junto con otros defectos congénitos que comprometen el críneo, la cara $y$ los huesos.
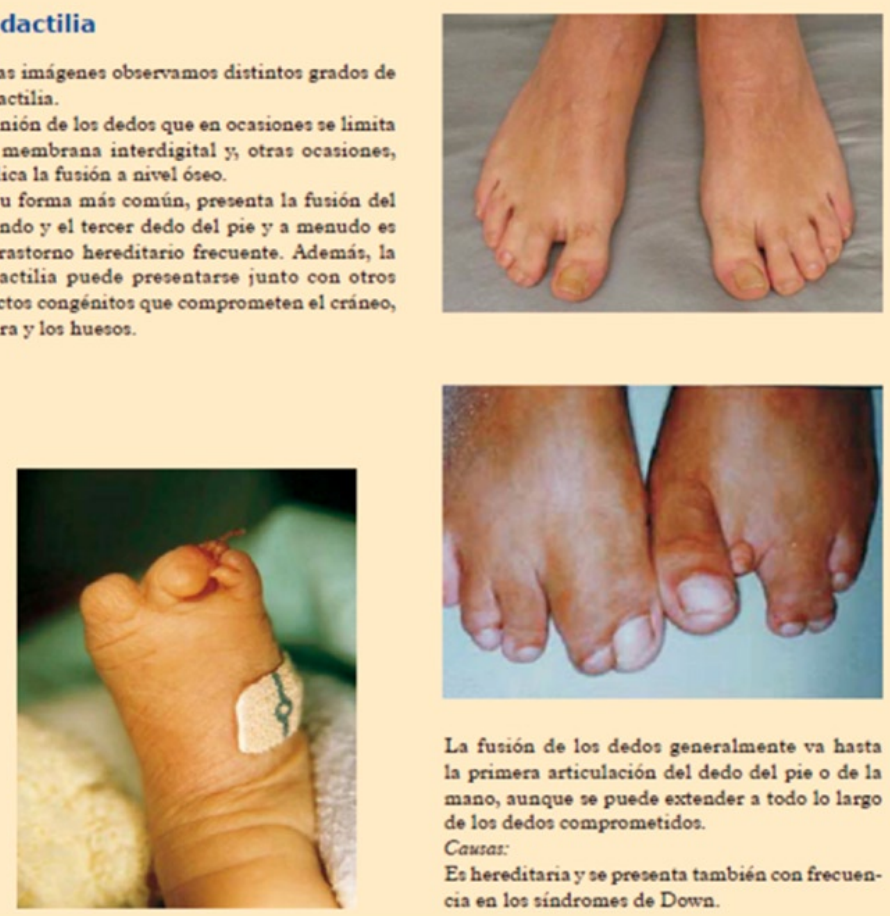

La fusión de los dedos generalmente va hasta la primera articulación del dedo del pie o de la mano, aunque se puede extender a todo lo largo de los dedos comprometidos.

Causar:

Es hereditariay se presenta también con frecuencia en los sindromes de Down.

Ilustración 11: Imagen extraída de la revista $E l$ peu 2007, n. ${ }^{\circ}$ 1: 42

\section{Conclusiones}

La funcionalidad de la imagen gráfica coadyuva a la eficacia descriptiva y comunicativa, incluso didáctica, del discurso académico y profesional. La utilidad de las imágenes visuales para la trasmisión de los conocimientos conceptuales y práctico-tecnológicos queda patente a partir del análisis de las ilus- 
traciones de nuestro corpus. La imagen es un elemento que constituye invariablemente un apoyo didáctico e ilustrativo al texto escrito y está representada por unos modelos como las figuras diagramáticas, la imagen clínica de un estado patológico, o el dibujo descriptor sintético de una técnica, pero resulta difícil ofrecer una definición completa y funcional que comprenda la totalidad de representaciones que corresponden a la imagen dentro de un discurso especializado.

Por nuestra parte hemos intentado establecer una escala gradual de figuratividad, que comenzaba con las ilustraciones más directamente icónicas y que culminaba con esquemas abstractos. El establecimiento de esta gradación resulta epistemológicamente útil en los discursos académicos en general, pero tiene una particular incidencia en algunas disciplinas de tipo clínico aplicado, como es el caso de la podología, donde la mostración de partes anatómicas, patologías o elementos instrumentales alcanza una importancia indudable, sin que por ello se deban ignorar los factores de la manipulación que indudablemente han de operar en las correspondientes representaciones. En segundo lugar, se han identificado distintas funciones -desde las ornamentales y ejemplificadoras hasta las estrictamente imprescindibles- que cumplen las imágenes insertadas en el texto de los distintos géneros integrantes de las revistas de especialidad podológica. Se ha hecho especial hincapié en una sección específica de una de las revistas analizadas, la sección denominada «Rincón de la imagen», caso curioso que pone de manifiesto la relevancia de la ilustración gráfica en este tipo de revistas.

\section{Referencias bibliográficas}

Allamel-Raffin, C.; A. Moktefi (eds.) (2011): «Definir l'image scientifique». Monogràfico de Visible: Images et dispositifs de visualisation scientifiques, . $^{\circ} 8$, Presses Universitaries de Limoges.

Bontems, V. (2011): «Le "cycle de l'image" selon Gilbert Simondon. Une définition génétique de l'image scientifique» en Allamel-Raffin, C.; A. MoKTEFI (eds.) (2011): 89-104.

EgGins, S.; J. R. MARTIN (2003): «El contexto como género. Una propuesta de lingüística funcional», Revista Signos 35 (54): 185-205.

Giardino, V. (2011): «Vers une classification diagrammatique» en AllamelRafFin, C.; A. Moktefi (2011): 185-201.

Novello Paglianti, N. (2011): «Le desin anatomique et l'image scientifique» en Allamel-Raffin, C.; A. Moktefi (eds.) (2011): 215-232. 
Payrató, L. (2012): «L'anàlisi del discurs al segle XXI: reflexions crítiques a l'entorn del context comunicatiu i la multimodalidat» en SALVAdor, V. (ed.): L'ull despert. Anàlisi crítica dels discursos d'avui, València, 3i4, 105-150.

Perales, F. J.; J. D. Jiménez (2002): «Las ilustraciones en la enseñanzaaprendizaje de las ciencias. Análisis de libros de texto», Enseñanza de las ciencias, 20 (3): 369-386.

Prieto Velasco, J. A. (2007): «Hacia un modelo de uso ilustraciones en el discurso científico-técnico», Sendebar, 18: 127-158.

Valero Sancho, J. L. (2001): La infografía. Técnicas, análisis y usos periodísticos, Barcelona, UAB/UJi/UPF/UV. 